\title{
Peer Pressure Is the Prime Driver of Risky Sexual Behaviors among School Adolescents in Addis Ababa, Ethiopia
}

\author{
Amsale Cherie $^{1 *}$, Yemane Berhane ${ }^{2}$ \\ ${ }^{1}$ School of Public Health, Addis Ababa University, Addis Ababa, Ethiopia; ${ }^{2}$ Addis Continental Institute of Public Health, Addis \\ Ababa, Ethiopia. \\ Email: *amsalec2002@yahoo.com, Yemaneberhane@ethionet.et, Yemane_b@hotmail.com
}

Received April 23 ${ }^{\text {rd }}, 2012$; revised May 28 ${ }^{\text {th }}, 2012$; accepted June 28 ${ }^{\text {th }}, 2012$

\begin{abstract}
Background: Understanding ecological factors that influence risky sexual behavior of adolescents is vital in designing and implementing sexual risk reduction interventions in specific contexts. Interventions undertaken without understanding the critical factors may not produce the desired results. Objective: The objective of this study was to identify the factors associated with adolescent risky sexual behavior among school adolescents in Addis Ababa, Ethiopia. Methods: This cross-sectional study was done among randomly selected school adolescents in Addis Ababa, Ethiopia. Data were collected by an anonymous self administered questionnaire. Risky sexual behavior was assessed by asking question about sexual activity, consistent condom use and faithfulness to a single partner. Logistic regression analysis was done to identify factors related to sexual behavior using the ecological framework. Result: Overall 377 (10.6\%) of the 723 sexually active students were involved in risky sexual practices. Risky sexual behavior was significantly and very strongly associated with perception of peers' involvement in sexual intercourse [AOR $=11.68$ (95\% CI: 8.76 15.58)]. Conclusion: This study demonstrated that peer pressure is the most important factor associated with risky sexual behavior among school adolescents in Addis Ababa. Interventions aimed at reducing sexual behavior among school adolescents should target adolescents as a group rather than individually.
\end{abstract}

Keywords: Risky Sexual Behavior; School; Peer Norms; Adolescent

\section{Introduction}

Risky sexual behavior predisposes young people to a variety of sexuality associated problems including HIV. Strategies to prevent the spread of HIV and other sexually transmitted infections have focused on abstinence, being faithful, condom use and delayed sexual activity. However available evidences show that significant proportion of adolescents are engaged in risky sexual behaviors that expose them to a variety of sexually transmitted infections including HIV [1-5].

Approximately half of the new HIV infections globally occur in the age group 15 to 24 years [6]. In Ethiopia about $90 \%$ of the people living with HIV are believed to have acquired the infection before the age of 25 mainly through unprotected sexual intercourse $[7,8]$.

Although significant proportion of young people in Ethiopia are known to be involved in risky sexual behavior such as early sexual initiation, multiple partner

\footnotetext{
${ }^{*}$ Corresponding author.
}

sexual relationships, low use of condom, and sex in exchange of money identifying the factors associated with these behaviors so far have been focused on individuallevel factors [9-11]. Extant literatures revealed that peer norms influence sexual initiation and subsequent sexual behaviors [12-14]. Adolescents who perceive their friends are engaged in sexual practices are more likely to adopt those same behaviors [12-14]. Sexual risk behavior is affected and effected by a complex web of factors at the individual, family, school and peer levels [15-17].

Understanding these interwoven and interconnected factors that influence sexual behaviors of adolescent is vital in designing and implementing sexual risk reduction interventions. Using the ecological framework in studying adolescent sexual behavior can widen the scope of investigation in assessing factors that influence adolescent sexual behaviors in specific contexts. Thus, this study was intended to assess the factors associated with risky sexual behavior among school adolescents using the ecological framework. 


\section{Methods and Materials}

This was a cross-sectional study conducted among high school adolescent living in Addis Ababa, Ethiopia. The city of Addis Ababa is divided into 10 sub cities and each sub city is divided into 10 districts. The study population was randomly selected using a multi-stage sampling method that aimed at selecting 3840 eligible students from 10 high schools in Addis Ababa. The total sample size was distributed to each school proportionate to their size. In the first stage schools were randomly selected from each sub city then sections were selected randomly from each school proportionate to the student population size.

Data were collected using a self administered questionnaire that had several sections dealing with sexual behaviors and elements of the ecological framework including individual, family, school and peer level factors. The questionnaire was primarily prepared in English based on similar questionnaires used elsewhere $[1,16,17]$ and then translated and administered in Amharic which is the official language of the country. Prior to the study a pretest was conducted in schools not selected for the study and the necessary adjustment in language and content was done. Data collection was facilitated by ten nurses under the supervision of two public health experts.

Risky sexual behavior was computed by considering several key questions, which included "have you ever had sexual intercourse, Have you had sex in the past 12 months how many partners have you had in the 12 months; have you consistently used condom during sexual intercourse in the past 12 months, and have you received or given gift/money at the exchange of sex". Those having more than one partner or not consistently used condom, or engaged in exchange sex in the last 12 months were considered to be in risky sexual behavior. Then, those engaged in risky sexual behavior were coded " 1 " and the remaining " 0 ".

The questionnaire also consisted of individual level factors such as sex, age, self-esteem, college aspirations, knowledge about HIV, perception of condom use self efficacy, attitude towards condom and perceived negotiation of condom use. Students were also asked about family factors such as parental education, parental connectedness, parental communication about sex, parental norm and parental monitoring. The questionnaire comprised of also questions related to school connectedness and peer factor perceived engagement of peers in sex.

The study received ethical approval from the Institution Review Board of Faculty of Medicine of Addis Ababa University. In addition, verbal consent of individual participants was obtained after being fully informed of the study purpose and procedures. Confidentiality and anonymity were ensured. No name or other identifying information was included in the instrument.

\section{Data Analysis}

Data analysis was done using SPSS version 15 statistical package. We first conducted bivariate analysis between risky sexual behavior as dependent and a range of independent variables. Then a series of four step regression models were fitted using the variables found to be significant in the bivariate analysis to assess associations between risky sexual behavior and various elements of the ecological framework-individual, parental, school and peer level factors. In the first step individual level variables such as sex, age, self-esteem, college aspirations, knowledge about HIV, perception of condom use self efficacy, attitude towards condom and perceived negotiation of condom use were entered. In the second step parental monitoring and parental norms towards premarital sex was added in the model. The third model comprised of the entry of school connectedness in the model. The fourth model included perceived engagement of peers in sex. Finally, we constructed a final reduced model, which included only those variables significantly associated with sexual risk behavior.

\section{Results}

From the 3840 eligible respondents, 3543 (92.5\%) in school adolescent fully responded to the self administered questionnaire. Of all the respondents nearly half 1789 (50.5\%) were females. Nearly a quarter of students were in the age group 15 - 16 years and more than half of students were living with both parents. One sixth of student's fathers and one fifth of students mothers were with out formal education. A total of 723 (20.4\%) students reported ever having sexual intercourse (Data not shown).

Risky sexual behavior of participants is depicted in Table 1. Over all 377 (10.6\%) of the study participants were involved in risky sexual behavior in the past 12 months sex. A total of 574 (79.4\%) of the sexually active students had reported that they have been sexually active in the 12 months preceding the survey, 262 (45.6\%) had sex with more than one sexual partner, 319 (55.6\%) didn't use condom consistently and 118 (20.6\%) were involved in sex at the exchange of money.

Model 1 (individual) variables predicted $26.1 \%$ of the variance in sexual activity. When parental factors were added in the model in the second step the explanatory power of the model increased to $32.9 \%$. School connectedness was added to the model in the third step. The third step accounted for $37.8 \%$ of the variance. In the fourth step peer level factor was entered. When perceived engagement of peers in sex was added in model 4 the explanatory power of the model increased to $54.3 \%$. The final model accounted for $58.5 \%$ of the variance in sexual activity. 
Table 1. Risky sexual practice among high school adolescents in Addis Ababa, Ethiopia.

\begin{tabular}{lc}
\hline \multicolumn{1}{c}{ Variables } & No (\%) \\
\hline Ever had sex & $723(20.4)$ \\
Yes & $2820(79.6)$ \\
No & \\
Had sex in the past 12 months & $574(79.4)$ \\
Yes & $149(20.6)$ \\
No & \\
Number of partners at past 12 months sex & $312(54.4)$ \\
One & $262(45.6)$ \\
Greater than one & \\
Condom use at the past 12 months sex & $255(44.4)$ \\
Yes & $319(55.6)$ \\
No & \\
Sex at the exchange of money & $118(20.6)$ \\
Yes & $456(79.4)$ \\
No & \\
Risky sexual behavior & $377(10.6)$ \\
Yes & $3166(89.4)$ \\
\hline No
\end{tabular}

The independent correlates of risky sexual behavior are shown in Table 2. Respondents were likely to experience risky sexual behavior if they had low knowledge of HIV [AOR = 1.50 (95\%CI: $1.15-1.96)$, reported low self esteem [AOR $=1.42(95 \% \mathrm{CI}$ : $1.06-1.89)]$ and manifested low perceived efficacy to use condom [AOR = 1.93 (95\%CI: 1.46 - 2.55)].

Parental monitoring was significantly associated with risky sexual behavior [AOR = 1.42 (95\%CI: 1.06 - 1.89)]. Restrictive parental norms towards sex were a protective from risky sexual behavior [AOR $=0.77$ (95\%CI: 0.61 0.99)]. Students who were less connected to school were more likely to be involved in risky sexual behavior than their counterparts [AOR $=1.39$ (95\%CI: $1.03-1.86)]$. Most importantly students who perceived their peers are involved in sexual relationships were more likely to report risky sex behavior compared to those who did not have this perception $[\mathrm{AOR}=11.68$ (95\%CI: $8.76-$ 15.58)].

\section{Discussion}

This study revealed that one in five high school students have initiated sexual activity and about half of those who initiated sex were involved in risky sexual practices. Analysis of the factors associated with risky sexual behavior using the ecological framework indicated peer pressure is the most important predictor.

The study used an extensive sampling procedure and large sample size to maximize the representation of the sample to high school students in Addis Ababa and similar settings. Although, social-desirability biases are likely and can lead to underestimation of risky sexual behaviors, efforts were made to minimize this bias by proving a safe environment to complete the questionnaire and omitting all identifying variables from the questionnaire to ensure anonymity. The cross sectional nature of the study does not allow the full exploitation of temporal relationships and establishing causality. Nonetheless the risky sexual behavior observed in this study is still very high requiring carefully designed interventions that consider breaking peer influences, the prime predictor of risky sexual behavior in this population.

Individual level factors had significant association with risky sexual behavior. In agreement with previous studies [18-24] low self esteem and perceived low self efficacy to use condom were significantly associated with risky sexual behavior in this study as well. Programs that are known to increase the self esteem of young people and condom use skill training need to be integrated in school curriculum to promote healthy sexual life for school adolescents.

In accordance with studies made elsewhere low parental monitoring and permissive parental norms were significantly associated with greater involvement in risky sexual behavior [25-29]. Parents are the primary socializing agents and have significant influence on their children's behavior. Up until know there is no institution or programme in Ethiopia providing training on the appropriate way of parenting. Therefore, training parents on how to nurture their children have supreme importance in risk behavior reduction and there by diminution of HIV acquisition.

Corroborating with previous studies adolescent who perceive their friends are engaged in risky sexual behavior, were more likely to adopt those same behaviors. $[18,29,30]$. Peers have significant influences on young peoples behavior. Therefore, strengthening school peer education programmes to create a culture of positive peer influence is critical.

Students who perceived connected to school were less likely to be engaged in risky sexual behavior in this study. There are also evidences that showed poor connectedness to school were significantly associated with risky sexual behavior [30-32]. Students need to get more opportunities to stay longer and safely in school environment to promote appropriate student-teacher relationship that can promote sexual risk reduction behaviors. Furthermore, interventions and programmes are needed that reinforce access to positive social connections at school and provide nurturing and caring social contexts in schools.

Encouraging safe sexual behavior is one of the strategies in the prevention of HIV and other sexually transmitted infections. The study clearly showed the priority intervention among high school students is to promote positive peer-to-peer influence to promote safer sexual behavior among high school students. At the same time, promoting appropriate parenting and improving the school environment can augment the effectiveness of peer targeted interventions.

This study assessed the determinants of sexual behavior at various levels of the ecological space. However, to 
Table 2. Independent correlates of risky sexual behavior among 3543 high school students in Addis Ababa, Ethiopia, 2009.

\begin{tabular}{|c|c|c|c|c|}
\hline \multirow{2}{*}{ Sources of effect } & \multicolumn{2}{|c|}{ Risky sexual behavior $(n=3543)$} & \multirow{2}{*}{ Un adjusted OR (95\%CI) } & \multirow{2}{*}{ Adjusted OR (95\%CI) } \\
\hline & Yes & No & & \\
\hline \multicolumn{5}{|c|}{ Model I: Individual factors } \\
\hline \multicolumn{5}{|l|}{ knowledge about HIV } \\
\hline Low & 272 & 2041 & $1.43(1.13-1.81)$ & $1.49(1.14-1.94)$ \\
\hline High & 105 & 1125 & Reference & Reference \\
\hline \multicolumn{5}{|l|}{ Self esteem } \\
\hline Low & 259 & 1356 & $2.93(2.33-3.68)$ & $1.43(1.07-1.92)$ \\
\hline High & 118 & 1810 & Reference & Reference \\
\hline \multicolumn{5}{|l|}{ Attitude towards condom } \\
\hline Negative & 274 & 1683 & $2.34(1.84-2.97)$ & $1.65(1.28-2.13)$ \\
\hline Positive & 103 & 1483 & Reference & Reference \\
\hline \multicolumn{5}{|c|}{ Perceived Self efficacy to use condom } \\
\hline No & 219 & 891 & $3.53(2.84-4.40)$ & $1.90(1.44-2.52)$ \\
\hline Yes & 158 & 2275 & Reference & Reference \\
\hline \multicolumn{5}{|c|}{ Model II: Parental factors } \\
\hline \multicolumn{5}{|l|}{ Parental monitoring } \\
\hline No & 253 & 1659 & $1.85(1.47-2.32)$ & $1.39(1.08$ - 1.79) \\
\hline Yes & 124 & 1507 & Reference & Reference \\
\hline \multicolumn{5}{|l|}{ Parental norms towards sex } \\
\hline Restrictive & 182 & 2011 & $0.53(0.43-0.66)$ & $0.78(0.61-0.99)$ \\
\hline Non-restrictive & 195 & 1155 & Reference & Reference \\
\hline \multicolumn{5}{|c|}{ Model III: School factors } \\
\hline \multicolumn{5}{|l|}{ School connectedness } \\
\hline Low & 104 & 433 & $2.40(1.87-3.08)$ & $1.37(1.02-1.84)$ \\
\hline High & 273 & 2733 & Reference & Reference \\
\hline \multicolumn{5}{|c|}{ Model IV: Peer factors } \\
\hline \multicolumn{5}{|c|}{ Perceived involvement of peers in sex } \\
\hline Yes & 92 & 101 & $9.79(7.20-13.32)$ & $11.49(8.49$ - 815.55) \\
\hline No & 285 & 3065 & Reference & Reference \\
\hline \multicolumn{5}{|l|}{ Final Model $P<0.1$} \\
\hline \multicolumn{5}{|l|}{ Knowledge about HIV } \\
\hline Low & 272 & 2041 & $1.43(1.13-1.81)$ & $1.50(1.15-1.96)$ \\
\hline High & 105 & 1125 & Reference & Reference \\
\hline \multicolumn{5}{|c|}{ Perceived self efficacy to use condom } \\
\hline No & 219 & 891 & $3.53(2.84-4.40)$ & $1.93(1.46-2.55)$ \\
\hline Yes & 158 & 2275 & Reference & Reference \\
\hline \multicolumn{5}{|l|}{ Self esteem } \\
\hline Low & 259 & 1356 & $2.93(2.33-3.68)$ & $1.42(1.06-1.89)$ \\
\hline High & 118 & 1810 & Reference & Reference \\
\hline \multicolumn{5}{|l|}{ Parental monitoring } \\
\hline No & 253 & 1659 & $1.85(1.47-2.32)$ & $1.42(1.09-1.83)$ \\
\hline Yes & 124 & 1507 & Reference & Reference \\
\hline Parental norms towards sex & & & & \\
\hline Restrictive & 182 & 2011 & $0.53(0.43-0.66)$ & $0.77(0.61-0.99)$ \\
\hline Non-restrictive & 195 & 1155 & Reference & Reference \\
\hline School connectedness & & & & \\
\hline Low & 104 & 433 & $2.40(1.87-3.08)$ & $1.39(1.03-1.86)$ \\
\hline High & 273 & 2733 & Reference & Reference \\
\hline Perceived involvement of peers & & & & \\
\hline Yes & 92 & 101 & $9.79(7.20-13.32)$ & $11.68(8.76-15.58)$ \\
\hline No & 285 & 3065 & Reference & Reference \\
\hline
\end{tabular}

better understand the causes of adolescent risky sexual behavior longitudinal investigations that track the antecedents of sexual behavior are needed. Secondly, studies on factors contributing to positive adolescent develop- ment are needed to assess the assets in and outside students so that, interventions and programmes which can foster positive behavior can be developed and implemented. 


\section{REFERENCES}

[1] CDC, "Youth Risk Behavior Surveillance-United States, 2009," Morbidity and Mortality Weekly Report, Vol. 59, No. SS-5, 2010, pp. 1-142.

[2] A. Cherie, G. Mitkie, S. Ismail and Y. Berhane, "Perceived Sufficiency and Usefulness of IEC Materials and Methods Related to HIV/AIDS among High School Youth in Addis Ababa, Ethiopia," African Journal of Reproductive Health, Vol. 9, No. 1, 2005, pp. 66-77.

[3] T. Barnett and J. Parkhurst, "HIV/AIDS: Sex, Abstinence, and Behavior Change," The Lancet Infectious Diseases, Vol. 5, No. 9, 2005, pp. 590-593. doi:10.1016/S1473-3099(05)70219-X

[4] E. M. Murphy, M. E. Greene, A. Mihailovic and P. Olupot- Olupot, "Was the 'ABC' Approach (Abstinence, Being Faithful, Using Condoms) Responsible for Uganda's Decline in HIV?” PLoS Medicine, Vol. 3, No. 9, 2006, p. e379.

[5] T. L. Lillie and B. Curbow, "Kenyan In-School Youths' Level of Understanding of Abstinence, Being Faithful and Consistent Condom Use Terms: Implications for HIVPrevention Programs,” Journal of Health Communication, Vol. 14, No. 3, 2009, pp. 276-292.

[6] Joint United Nations on HIV/AIDS (UNAIDS), "UNAIDS Report on the Global AIDS Epidemic," Geneva, 2010.

[7] Federal Ministry of Health/National HIV/AIDS Prevention and Control Office, "AIDS in Ethiopia Sixth Report,” Addis Ababa, 2006.

[8] Federal Democratic Republic of Ethiopia, Federal HIV/AIDS Prevention and Control Office, "Report on Progress towards Implementation of the UN Declaration of Commitment on HIV/AIDS,” Addis Ababa, 2010.

[9] H. Astatke, M. Black and R. Serpell, "Use of Jessor's Theoretical Framework of Adolescent Risk Behavior in Ethiopia: Implications for HIV/AIDS Prevention,” Northeast African Studies, Vol. 7, No. 1, 2000, pp. 63-84. doi:10.1353/nas.2004.0001

[10] M. Molla, Y. Berhane and B. Lindtjørn, "Traditional Values of Virginity and Sexual Behaviour in Rural Ethiopian Youth: Results from a Cross-Sectional Study,” BMC Public Health, Vol. 8, No. 1, 2008, p. 9. doi:10.1186/1471-2458-8-9

[11] F. Mazengai and A. Worku, "Age at Sexual Initiation and Factors Associated with It among Youths in North East Ethiopia,” Ethiopian Journal of Health Development, Vol. 23, No. 2, 2009, pp. 154-162.

[12] C. C. Henrich, K. A. Brookmeyer, L. A. Shrier and G. Shahar, "Supportive Relationships and Sexual Risk Behavior in Adolescence: An Ecological Transactional Approach,” Journal of Pediatric Psychology, Vol. 31, No. 3, 2006, pp. 286-297. doi:10.1093/jpepsy/jsj024

[13] J. Jaccard, H. Blanton and T. Dodge, "Peer Influences on Risk Behavior: An Analysis of the Effects of a Close Friend,” Developmental Psychology, Vol. 41, No. 1, 2005, pp. 135-147. doi:10.1037/0012-1649.41.1.135

[14] L. O’Donnell, A. Stueve, R. Wilson-Simmons, K. Dash,
G. Agronick and V. Jean Baptiste, "Heterosexual Risk Behaviors among Urban Young Adolescents," Journal of Early Adolescence, Vol. 26, No. 1, 2006, pp. 87-109.

[15] J. Di C. Ralph, L. Salazar and R. Crosby, “A Review of STD/HIV Preventive Interventions for Adolescents: Sustaining Effects Using an Ecological Approach,” Journal of Pediatric Psychology, Vol. 32, No. 8, 2007, pp. 888906. doi:10.1093/jpepsy/jsm056

[16] A. Cherie and Y. Berhane, "Oral and Anal Sex Practices among High School Youth in Addis Ababa, Ethiopia," BMC Public Health, Vol. 12, 2012, p. 5. doi:10.1186/1471-2458-12-5

[17] J. Di C. Ralph, L. Salazar and R. Crosby, “A Review of STD/HIV Preventive Interventions for Adolescents: Sustaining Effects Using an Ecological Approach,” Journal of Pediatric Psychology, Vol. 32, No. 8, 2007, pp. 888906. doi:10.1093/jpepsy/jsm056

[18] T. L. Boone and E. S. Lefkowitz, "Safer Sex and the Health Belief Model: Considering the Contributions of Peer Norms and Socialization Factors," Journal of Psychology \& Human Sexuality, Vol. 16, No. 1, 2004, pp. 51-68. doi:10.1300/J056v16n01_04

[19] R. A. Crosby, R. J. Di Clemente, G. M. Wingood, L. F. Salazar, K. Harrington, S. L. Davies, et al., "Identification of Strategies for Promoting Condom Use: A Prospective Analysis of High-Risk African American Female Teens,” Prevention Science, Vol. 4, No. 4, 2003, pp. 263-270. doi:10.1023/A:1026020332309

[20] R. A. Crosby, R. J. Di Clemente, G. M. Wingood, B. K. Cobb, K. Harrington, et al., "Condom Use and Correlates of African American Adolescent Females' Infrequent Communication with Sex Partners about Preventing Sexually Transmitted Diseases and Pregnancy,” Health Education \& Behavior, Vol. 29, No. 2, 2002, pp. 219-231.

[21] R. A. Crosby, R. J. DiClemente, G. M. Wingood, C. Sionean, B. K. Cobb and K. Harrington, "Correlates of Unprotected Vaginal Sex among African American Female Adolescents: Importance of Relationship Dynamics," Archives of Pediatrics \& Adolescent Medicine, Vol. 154, No. 9, 2000, pp. 893-899.

[22] R. Crosby, R. J. Di Clemente, G. M. Wingood, C. Sionean, B. K. Cobb, K. Harrington, et al., "Correct Condom Application among African-American Adolescent Females: The Relationship to Perceived Self-Efficacy and the Association to Confirmed STDs," Journal of Adolescent Health, Vol. 29, No. 3, 2001, pp. 194-199. doi:10.1016/S1054-139X(01)00273-7

[23] S. Kalichman, J. A. Stein, R. Malow, C. Averhart, J. Devieux, T. Jennings, et al., "Predicting Protected Sexual Behaviour Using the Information-Motivation-Behaviour Skills Model among Adolescent Substance Abusers in Court-Ordered Treatment," Psychology, Health \& Medicine, Vol. 7, No. 3, 2002, pp. 327-338. doi:10.1080/13548500220139368

[24] L. F. Salazar, R. J. DiClemente, G. M. Wingood, R. A. Crosby, K. Harrington, S. Davies, et al., "Self-Concept and Adolescents' Refusal of Unprotected Sex: A Test of Mediating Mechanisms among African American Girls,” Prevention Science, Vol. 5, No. 3, 2004, pp. 137-149. 
[25] R. A. Crosby, R. J. DiClemente, G. M. Wingood, B. K. Cobb, K. Harrington, S. L. Davies, et al., "HIV/STDProtective Benefits of Living with Mothers in Perceived Supportive Families: A Study of High-Risk African American Female Teens," Preventive Medicine: An International Journal Devoted to Practice and Theory, Vol. 33, No. 3, 2001, pp. 175-178.

[26] R. A. Crosby, R. J. DiClemente, G. M. Wingood and K. Harrington, "HIV/STD Prevention Benefits of Living in Supportive Families: A Prospective Analysis of High Risk African-American Female Teens," American Journal of Health Promotion, Vol. 16, No. 3, 2002, pp. 142145. doi:10.4278/0890-1171-16.3.142

[27] R. A. Crosby, R. J. DiClemente, G. M. Wingood, D. L. Lang and K. Harrington, "Infrequent Parental Monitoring Predicts Sexually Transmitted Infections among LowIncome African American Female Adolescents," Archives of Pediatrics \& Adolescent Medicine, Vol. 157, No. 2, 2003, pp. 169-173.

[28] C. McNeely, M. L. Shew, T. Beuhring, R. Sieving, B. C. Miller and R. W. Blum, "Mothers' Influence on the Timing of First Sex among 14- and 15-Year-Olds,” Journal of
Adolescent Health, Vol. 31, No. 3, 2002, pp. 256-265. doi:10.1016/S1054-139X(02)00350-6

[29] D. J. Whitaker and K. S. Miller, "Parent-Adolescent Discussions about Sex and Condoms: Impact on Peer Influences of Sexual Risk Behavior," Journal of Adolescent Research, Vol. 15, No. 2, 2000, pp. 251-273. doi:10.1177/0743558400152004

[30] C. T. Pedlow and M. P. Carey, "Developmentally Appropriate Sexual Risk Reduction Interventions for Adolescents: Rationale, Review of Interventions, and Recommendations for Research and Practice," Annals of Behavioral Medicine, Vol. 27, No. 3, 2004, pp. 172-184. doi:10.1207/s15324796abm2703_5

[31] D. R. Voisin, L. F. Salazar, R. Crosby, R. J. DiClemente, W. L. Yarber and M. Staples-Horne, "Teacher Connectedness and Health-Related Outcomes among Detained Adolescents,” Journal of Adolescent Health, Vol. 37, No. 4, 2005, pp. 337.e17-337.e23.

[32] D. Kirby, "Understanding What Works and What Doesn't in Reducing Adolescent Sexual Risk-Taking," Family Planning Perspectives, Vol. 33, No. 6, 2001, pp. 276-281. doi:10.2307/3030195 